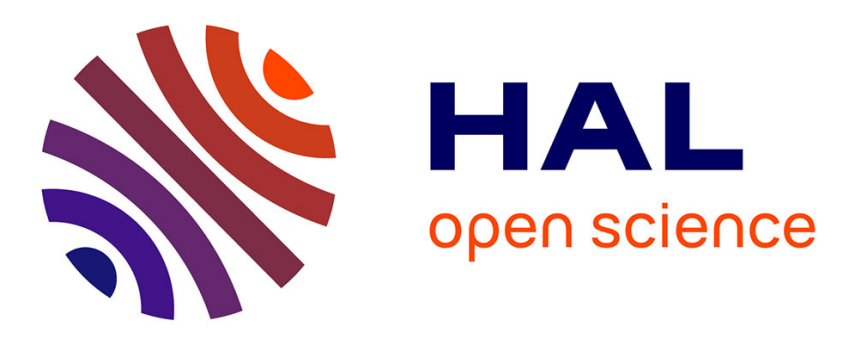

\title{
Interfacial interactions as an electrochemical tool to understand Mo-based catalysts for the hydrogen evolution reaction
}

Nicolas Dubouis, Chunzhen Yang, Robin Beer, Lucie Ries, Damien Voiry, Alexis Grimaud

\section{To cite this version:}

Nicolas Dubouis, Chunzhen Yang, Robin Beer, Lucie Ries, Damien Voiry, et al.. Interfacial interactions as an electrochemical tool to understand Mo-based catalysts for the hydrogen evolution reaction. ACS Catalysis, In press, 10.1021/acscatal.7b03684 . hal-02388366v2

\section{HAL Id: hal-02388366 \\ https://hal.sorbonne-universite.fr/hal-02388366v2}

Submitted on 20 Dec 2017

HAL is a multi-disciplinary open access archive for the deposit and dissemination of scientific research documents, whether they are published or not. The documents may come from teaching and research institutions in France or abroad, or from public or private research centers.
L'archive ouverte pluridisciplinaire HAL, est destinée au dépôt et à la diffusion de documents scientifiques de niveau recherche, publiés ou non, émanant des établissements d'enseignement et de recherche français ou étrangers, des laboratoires publics ou privés. 
Subscriber access provided by BUPMC - Bibliothèque Universitaire Pierre et Marie Curie

\section{Article}

\section{Interfacial interactions as an electrochemical tool to understand Mo-based catalysts for the hydrogen evolution reaction}

Nicolas Dubouis, Chunzhen Yang, Robin Beer, Lucie Ries, Damien Voiry, and Alexis Grimaud

ACS Catal., Just Accepted Manuscript • DOI: 10.1021/acscatal.7b03684 • Publication Date (Web): 13 Dec 2017

Downloaded from http://pubs.acs.org on December 14, 2017

\section{Just Accepted}

"Just Accepted" manuscripts have been peer-reviewed and accepted for publication. They are posted online prior to technical editing, formatting for publication and author proofing. The American Chemical Society provides "Just Accepted" as a free service to the research community to expedite the dissemination of scientific material as soon as possible after acceptance. "Just Accepted" manuscripts appear in full in PDF format accompanied by an HTML abstract. "Just Accepted" manuscripts have been fully peer reviewed, but should not be considered the official version of record. They are accessible to all readers and citable by the Digital Object Identifier (DOI®). "Just Accepted" is an optional service offered to authors. Therefore, the "Just Accepted" Web site may not include all articles that will be published in the journal. After a manuscript is technically edited and formatted, it will be removed from the "Just Accepted" Web site and published as an ASAP article. Note that technical editing may introduce minor changes to the manuscript text and/or graphics which could affect content, and all legal disclaimers and ethical guidelines that apply to the journal pertain. ACS cannot be held responsible for errors or consequences arising from the use of information contained in these "Just Accepted" manuscripts. 


\title{
Interfacial interactions as an electrochemical tool to understand
} Mo-basedcatalysts for the hydrogen evolution reaction

\author{
Nicolas Dubouis, ${ }^{1}$ Chunzhen Yang, ${ }^{1}$ Robin Beer, ${ }^{1}$ Lucie Ries, ${ }^{2}$ Damien Voiry ${ }^{2}$ and Alexis \\ Grimaud*1,3,4 \\ ${ }^{1}$ Collège de France, 11 Place Marcelin Berthelot, 75231 Paris, France \\ ${ }^{2}$ IEM, University of Montpellier, CNRS, ENSCM, Montpellier 34095, France \\ ${ }^{3}$ Réseau sur le Stockage Electrochimique de l'Energie (RS2E), FR CNRS 3459, France \\ ${ }^{4}$ Sorbonne Universités - UPMC Univ. Paris 06, 4 place Jussieu, F-75005 Paris, France \\ *corresponding author: alexis.grimaud@college-de-france.fr
}

\begin{abstract}
Crystalline and amorphous transition metal chalcogenides such as $\mathrm{MoS}_{2}$ are currently recognized as state-of-the-art non-precious transition metal catalysts for the hydrogen evolution reaction (HER). Nevertheless, despite numerous studies dedicated to their electrocatalytic activities, the exact nature of the active sites as well as their interaction with interfacial water remain largely elusive. In this work, amorphous and crystalline $\mathrm{MoS}_{2}$ catalysts were prepared by electrodeposition and chemical exfoliation respectively, and compared with other Mo-based compounds. Herein, we show thatall those compounds exhibit two reduction mechanisms in low proton concentration: the proton reduction occurring at low overpotentialfollowed by the water reduction at higher overpotential.We show that both the chemical composition and the structure of the catalyst influence the activity of the proton reduction, but that none of those materialsefficiently catalyzes the water reduction. Finally, we could demonstrate by using different cations $\left(\mathrm{Li}^{+}, \mathrm{Na}^{+}\right.$and $\left.\mathrm{K}^{+}\right)$or using deuterated electrolytes that the active sites for the proton reduction mechanism is probably different for amorphous and exfoliated crystalline $\mathrm{MoS}_{2}$
\end{abstract}


Keywords: Hydrogen evolution reaction, molybdenum disulfide, interfacial interactions, solvation effect, isotopic effect,active sites determination

\section{Introduction}

In order to match the increasing demand for electricity storage required by the production of carbon free electricity using intermittent sources such as wind or solar energy, efficient solutions are required. Lithium-ions battery and new battery technologiessuch as $\mathrm{Na}$-ions, $\mathrm{Li}_{-} \mathrm{O}_{2}$, $\mathrm{Li}-\mathrm{S}$, molten salt batteries or elseare promising technologies. However they are suffering from several issues such as recyclability, safety, low energy density, etc ${ }^{1,2}$.Dihydrogen $\left(\mathrm{H}_{2}\right)$ appears as a viable candidate as energy carrier owing from its energy density of 33,500 Wh kg-1 well above other carriers such as gasoline (with a theoretical energy density of $12,000 \mathrm{Wh} \mathrm{kg}^{-1}$ ) or other energy storage/conversion technologies such as Li-ion batteries $\left(\approx 400 \mathrm{Wh} \mathrm{kg}^{-1}\right)$. Different solutions currently exist for the production of dihydrogen, and among them water electrolysis appears as one of the most promising and cost-effective way to produce carbon-free hydrogen at large scale ${ }^{3}$.

Nevertheless, electrochemical water splitting $\left(2 \mathrm{H}_{2} \mathrm{O}_{(\mathrm{l})}=2 \mathrm{H}_{2(\mathrm{~g})}+\mathrm{O}_{2(\mathrm{~g})}\right)$ currently suffers from large overpotentials due to the slow kinetics at the electrodes, hence requiring the use of electrocatalysts.At the anode side, transition metal oxides, such as $\mathrm{IrO}_{2}$ or $\mathrm{RuO}_{2}$, and oxy-hydroxides are currently consideredas the most active catalysts for the oxygen evolution reaction (OER: $2 \mathrm{H}_{2} \mathrm{O}_{(\mathrm{I})}+$ $\left.4 \mathrm{e}^{-}=4 \mathrm{H}^{+}+\mathrm{O}_{2(\mathrm{~g})}\right)$ and efforts are devoted to improve their stability and performances ${ }^{4,5}$. Regarding the cathode where the hydrogen evolution reaction (HER: $2 \mathrm{H}^{+}+2 \mathrm{e}^{-}=\mathrm{H}_{2(\mathrm{~g})}$ ) takes place, platinum is currently widely recognized as state-of-the-art catalyst and used in industrial alkaline electrolyzers which led to extensivefundamental studiesthrough the use of single crystals or thin films. Nevertheless,questions still remain aboutthe electrochemical behavior of $\mathrm{Pt}$ with recent works pointing outtowards drastic effects of the $\mathrm{pH}$ on the reaction mechanism and kinetics ${ }^{6-11}$. Despite 
being the most active HER catalyst, the implementation of Pt into electrochemical devices suffers from its high cost and scarcity which led to a race towards finding cost-effective and abundant HER catalysts. Using the hydrogen adsorption as a descriptor for the HER activity, $\operatorname{MoS}_{2}$ was proposedas a promising catalysts based on its neither too strong nor too weak hydrogen binding ${ }^{12,13}$.Further works werethen carried out to identify the edges of $\mathrm{MoS}_{2}$ grown by chemical vapor deposition (CVD) as active sitesthanks to its low free energy barrier for proton absorption ${ }^{14-16}$. Following this initial demonstration of $\mathrm{MoS}_{2}$ as a potential HER catalyst, numerous works devoted to understand the origin for this very large activity. For instance, Voiry et al. reported the conversion from bulk semiconductor $2 \mathrm{H}-\mathrm{MoS}_{2}$ into metallic $1 T-\mathrm{MoS}_{2}$ nanosheets and attributed the high activity of this material to the increased active site numbers and the improved charge transfer ${ }^{17,18}$ whilesulfur vacancies in the basal plane have also been considered as active sites for the HER by others ${ }^{19}$. Nevertheless, the different preparation methods often used for these materials make that the determination of the HER intermediates andmechanism on those compounds still remains largely elusive.

Aside from the works on crystalline $\mathrm{MoS}_{2}$, a new class of HER catalysts emerged lately, namely the amorphous andelectrodeposited $\operatorname{MoS}_{x}^{20,21}$. While the initial stoichiometry for these films is of debate, they undergo an activation step prior to HER potential so to reach an active state with a stoichiometry close to $\mathrm{MoS}_{2}{ }^{21}$. Recently, attempts to rationalize the HER mechanism and the activity for amorphous $\operatorname{MoS}_{x}$ catalysts were made ${ }^{22,23}$ but some crucial points such as the precise nature of the active sites remain unclear.Hence, while striking similarities can be seen between these two classes of catalysts, crystalline and amorphous chalcogenides, the lack of systematic studies hampers drawing definitive conclusions regarding the nature of the active sites and/or the mechanism which would allow material scientists to design better and more efficient low-cost transition metal sulfides as HER catalysts.

Intrigued by the similarities existing between crystalline $\mathrm{MoS}_{2}$ and amorphous $\mathrm{MOS}_{\mathrm{x}}$ HER catalysts, we therefore decided to embark into a comprehensive studyfor the HER mechanism on the surface of 
Mo-based catalysts. For that, we compared different Mo-based catalysts such as metallic Mo, bulk $\mathrm{MoO}_{3}$ and $\mathrm{MoS}_{2}\left(\mathrm{~b}-\mathrm{MoS}_{2}\right)$, exfoliated 1T-MoS nanosheets (1T-MoS $)$ and electrodeposited MoS film $\left(\mathrm{a}-\mathrm{MoS}_{\mathrm{x}}\right)$.We first demonstrate that the $\mathrm{pH}$ dependent HER mechanism previously reported for noble metal is ubiquitous and applies to every Mo-based catalyst,before tostudy the hydrogen adsorption on these different catalysts by examining a series of electrolytes.Doing so, we set up a new methodology to gain deeper insights into the reaction intermediates on the surface of HER catalysts.

\section{Resultsand discussion}

\section{Comparison of $\mathrm{MoS}_{2}$-based catalysts with other Mo-based catalysts:}

\section{fromproton to water reduction}

To assess the role of composition and structure on the HER performances of Mo-based catalysts, cyclic voltammetry experiments were carried out using a rotating disk electrode (RDE) in $1 \mathrm{M} \mathrm{H}_{2} \mathrm{SO}_{4}$ solution. Results shown in Figure 1 confirm the ability of both $1 \mathrm{~T}-$ MoS $_{2}$ nanosheets and electrodeposited $\mathrm{MoS}_{\mathrm{x}}$ films to efficiently reduce protons, with both catalysts exhibiting relatively low overpotentials of around $200-250 \mathrm{mV}$ at $10 \mathrm{~mA} / \mathrm{cm}^{2}$ geom. Moreover, Tafel slopes of about $45 \mathrm{mV}$ per decade were found for both catalysts, in agreement with previous reports ${ }^{17,20,24}$. Hence, we first confirm that even if they demonstrate lower HER activity than Pt (almost no overpotential and Tafel slope as low as $26 \mathrm{mV}$ per decade), both amorphous and crystalline $\mathrm{MoS}_{2}$ perform well as HER catalysts with similar performances and metrics. On the contrary, molybdenum metal shows greater overpotential (of around $500 \mathrm{mV}$ at $10 \mathrm{~mA} / \mathrm{cm}^{2}$ geom) associated with a very large Tafel slope greater than $110 \mathrm{mV}$ per decade. Interestingly, both overpotentials and Tafel slopes are reduced when bulk molybdenum oxides and sulfides are used compared to metallic molybdenum.

As a general comment, caution must be exercised when comparing the HER activity for the different catalysts. Indeed, one should note the difficulty to accurately determine the active surface area for exfoliated $1 \mathrm{~T}-\mathrm{MoS}_{2}$ compounds as well as for $\mathrm{MoS}_{\mathrm{x}}$ electrodeposited thin films, which could lead to 
misevaluation of the exchange current densities. Nevertheless, this would not change the Tafel slope which is intrinsic to the material and is of prime importance for large scale application. A better understanding of the morphology of bulk materials as well asnanosheets and electrodeposited films would be required to properly compare their activity. Nevertheless, when normalized by BET surface area (Fig. S1), comparable HER activities were found for the three bulk materials at $\mathrm{pH} 0$. Therefore, our experimental results suggest that the HER mechanism at low $\mathrm{pH}$ is very sensitive 1) to the chemical composition, with sulfides being consistently better catalysts than metal or oxides ${ }^{25}$, and 2) to the structure of the catalyst, with nanosheets or amorphous films most likely demonstrating better performances than bulk $\mathrm{MoS}_{2}$ when normalized by true surface area (Fig. S1). 
Figure 1. a) Polarization curves in $1 \mathrm{M} \mathrm{H}_{2} \mathrm{SO}_{4}(\mathrm{pH}=0.0)$ in $\mathrm{Ar}$ at $1,600 \mathrm{rpm}$ with a $20 \mathrm{mV} \mathrm{s}$ sweeping rate and b) corresponding Tafel plots and Tafel slopes values (in $\mathrm{mV} /$ decade) recorded over different electrode materials. Pt referring to a polycristalline platinum electrode-(pink), a-MoS $\mathrm{x}_{\mathrm{x}}$ referring to the electrodeposited $\mathrm{MoS}_{x}$ films in (black), 1T-MoS 2 referring to the exfoliated 1T$\mathrm{MoS}_{2}$ nanosheets (red), $\mathrm{MoO}_{3}$ referring to commercial molybdenum oxide bulk (darkblue), b-MoS referring to commercial $\mathrm{MoS}_{2}$ bulk (green) and Mo referring to commercial Mo metal naoparticles in (light blue).

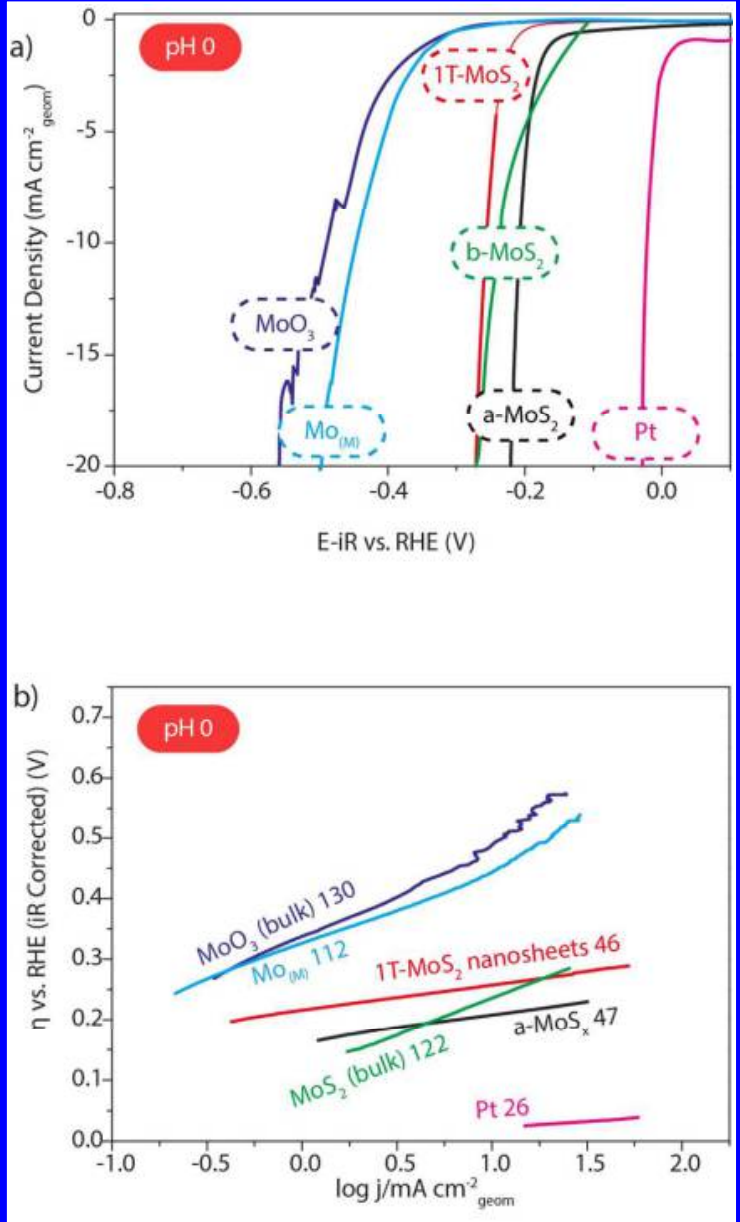

To gain deeper insights about the HER mechanism on the surface of Mo-based catalysts, electrochemical measurements were then performed at $\mathrm{pH} 4$. This study is inspired by recent reports demonstrating that despite lacking any thermodynamical justification (i.e. the standard potential for the water reduction $E^{\circ}\left(\mathrm{H}_{2} \mathrm{O} / \mathrm{H}_{2}\right)$ is expected to be the same as the one for proton reduction $\left.E^{\circ}\left(H^{+} / H_{2}\right)\right)$, several HER mechanisms can occur on the surface of precious metals such as platinum, 
gold or iridium ${ }^{7,8}$. Hence, while at high proton concentration the HER mechanism involves the reduction of hydronium ions $\left(\mathrm{H}_{3} \mathrm{O}^{+}+\mathrm{e}^{-}->1 / 2 \mathrm{H}_{2}+\mathrm{H}_{2} \mathrm{O}\right)$, a second mechanism was observed when lowering the proton concentration (at $\mathrm{pH} \geq 3$ ) where the reduction/splitting of water takes place $\left(\mathrm{H}_{2} \mathrm{O}+\mathrm{e}^{-}->1 / 2 \mathrm{H}_{2}+\mathrm{OH}^{-}\right)^{7,8}$. In contrast with the results previously obtained at lower pH (Fig. 1), the Tafel slope was found invariant and above $200 \mathrm{mV}$ per decade at $\mathrm{pH} 4$ for all the Mo-based catalysts (Fig. 2). Interestingly, a similar slope was obtained with Pt, which HER activity at pH 4 is also largely reduced. These results indicate that the mechanism for which water is reduced is ubiquitous to every HER catalyst, those demonstrating good performances at low $\mathrm{pH}$ as well as those performing poorly. These similarities between all these materials would indicate that Pt or Mo-based surfaces present no or almost no catalytic activity towards this reaction. This finding would also imply that the HER activity is, under these conditions, mainly limited by the energy necessary to break the $\mathrm{O}-\mathrm{H}$ bond of the water molecule ( $\mathrm{H}-\mathrm{O}$ bonds in $\mathrm{H}_{2} \mathrm{O}$ molecule are about $493 \mathrm{~kJ} \mathrm{~mol}^{-1}$, compared to around $20 \mathrm{~kJ}$ $\mathrm{mol}^{-1}$ for a typical hydrogen bond). Going further into that direction, one can easily envision that once enough energy has been provided to the system so to break the $\mathrm{O}-\mathrm{H}$ bond, the hydrogen adsorption (Volmer) step as well as the following step, either Tafel or Heyrovsky, would be downhill in energy. This situation drastically contrasts with the HER proceeding through hydronium reduction for which the energy of the intermediates formed on the surface of the catalyst during the reaction controls the catalytic activity, as shown by the different Tafel slopes measured for all the materials studied in this work.

Moreover, bulk $\mathrm{Mo}$ and $\mathrm{MoO}_{3}$ materials tested in $1 \mathrm{M} \mathrm{H}_{2} \mathrm{SO}_{4}$ electrolyte suffered from a rapid decay of the HER activity over about 20 cycles, suggesting drastic dissolution or leaching processes (Fig. S2). These mechanical instabilities could be at the origin for the signal noisiness observed for these compounds upon cycling in Fig. 1. In contrary, electrodes tested at $\mathrm{pH}=4$ are activated upon cycling (Fig. S3). This activation could be the consequence of an increased in surface area by 1) increasing the porosity of the particles thanks to an electrochemical leaching or 2) modifying the morphology by exfoliation induced by the $\mathrm{H}_{2}$ generation, as suggested recently for similar layered compounds ${ }^{26}$ 


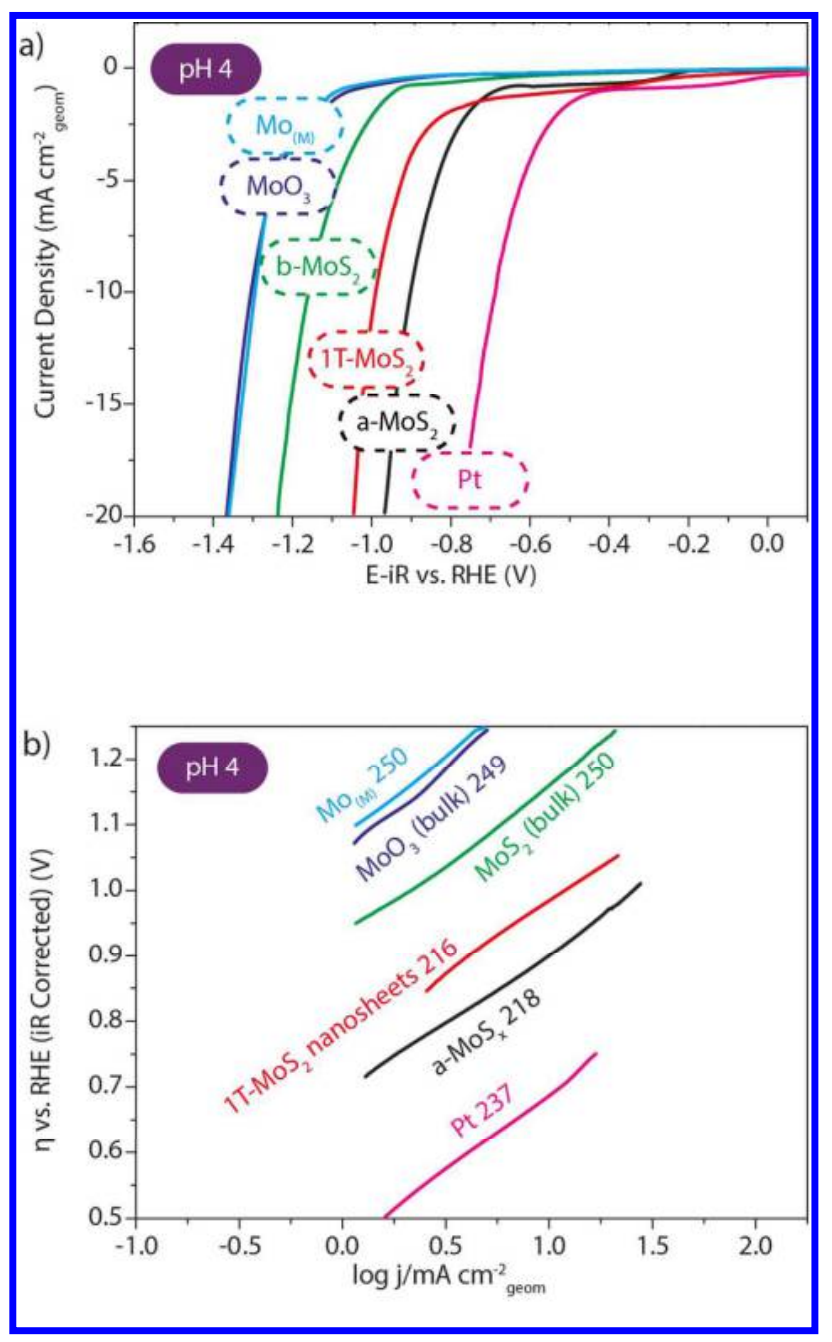

Figure 2. a) Polarization curves over different electrode materials in $0.18 \mathrm{mMH}_{2} \mathrm{SO}_{4}(\mathrm{pH}=4.0)$ recorded in $\mathrm{Ar}$ at 1,600 rpm at a rate of $20 \mathrm{mV} \mathrm{s}^{-1}$ and b) corresponding Tafel plots and Tafel slopes values (in $\mathrm{mV} /$ decade).Ptreferring to a polycristallineplatinumelectrode (pink), a-MoS referring to $^{2}$ the electrodeposited $\operatorname{MoS}_{x}$ films in(black), 1T-MoS 2 referring to the exfoliated 1T$\mathrm{MoS}_{2}$ nanosheets(red), $\mathrm{MoO}_{3}$ referring to commercial molybdenum oxide bulk (darkblue), b$\mathrm{MoS}_{2}$ referring to commercial $\mathrm{MoS}_{2}$ bulk (green) and Mo referring to commercial Mo metal nanoparticles in (light blue). 


\section{pH dependence study for amorphous and exfoliated $\mathrm{MoS}_{2}$}

To further support the ubiquity of these two mechanisms, we carried out a $\mathrm{pH}$ dependence study for the amorphous a-MoS and exfoliated 1T-MoS . When the proton concentration is high enough (i.e. at $\mathrm{pH} \leq 1$ ), the HER activity remains independent on the $\mathrm{pH}$ for the two compounds. This observation is consistent with a classical HER mechanism for which proton is the reactant and its reduction proceeds through twoproton-coupled electron transfer (PCET). Furthermore, Tafel slopes of around $45 \mathrm{mV}$ per decade were measured for the two catalysts in this $\mathrm{pH}$ range, which could indicate a Volmer $\left(\mathrm{H}^{+}+\mathrm{e}^{-}->\mathrm{H}_{\mathrm{ads}}\right) /$ Heyrovsky $\left(\mathrm{H}_{\mathrm{ads}}+\mathrm{H}^{+}+\mathrm{e}^{-}->\mathrm{H}_{2}\right)$ mechanism, with the Heyrovsky step being the rate determining step ${ }^{22}$. Nevertheless, even if Tafel slopes are commonly used to identify the HER mechanism, it should be reminded that many assumptions, such as the homogeneous distribution of active sites on the surface of the catalyst, are used to calculate theoretical Tafel slopes. Special care must then be exercised, especially for the exfoliated nanosheets where active sites are reported to be concentrated on the edges of the sheets. Hence, these assumptions are probably not fulfilled and a mechanistic interpretation from Tafel slopes may not be accurate. 

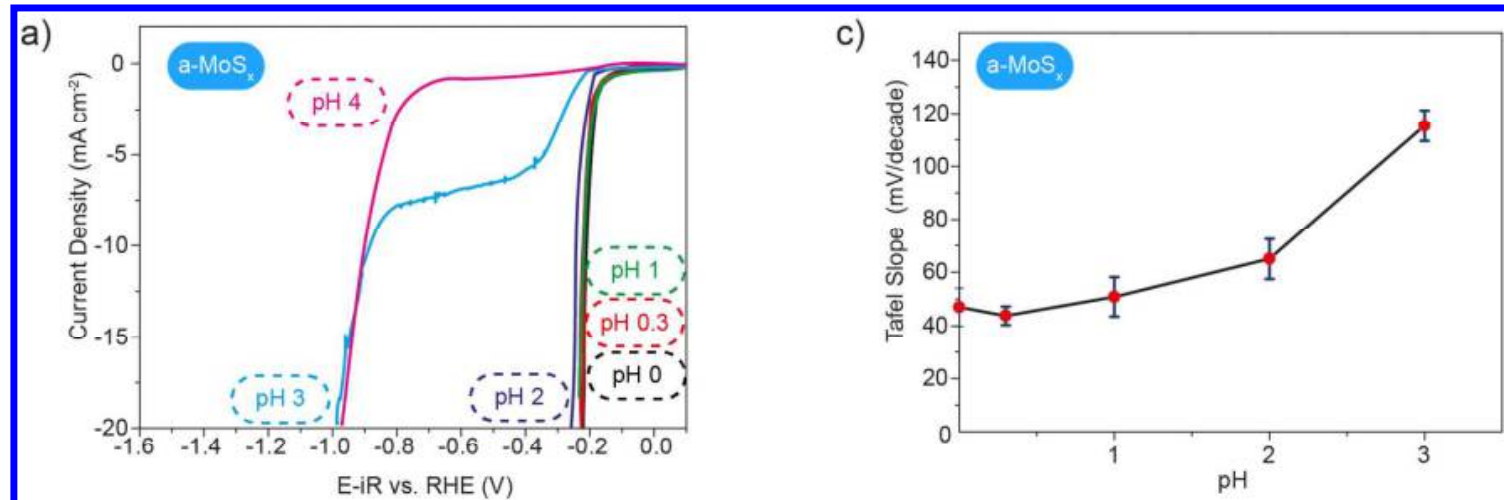

b)

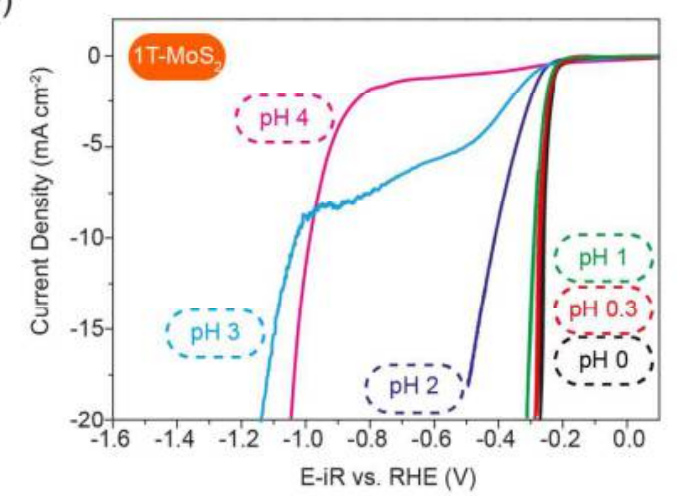

d)

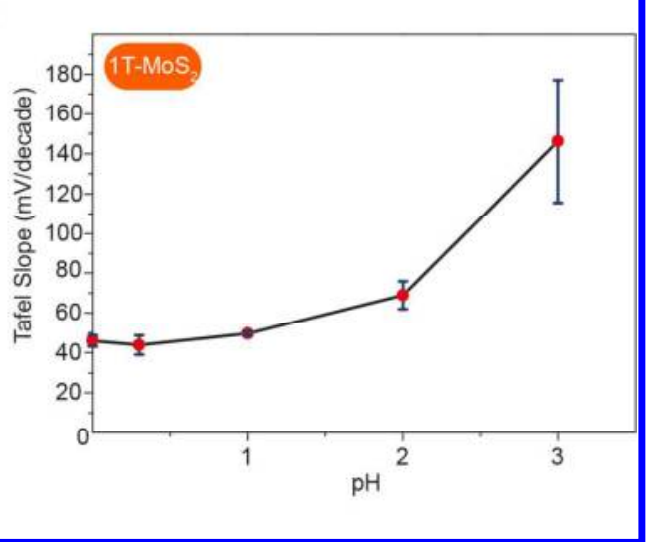

Figure 3. Polarization curves recorded at pH 0 (black), pH 0.3 (red), $\mathrm{pH} 1$ (green), $\mathrm{pH} 2$ (dark blue), pH 3 (light blue) and $\mathrm{pH} 4$ (pink) in $\mathrm{H}_{2} \mathrm{SO}_{4}$ electrolytesover a) electrodeposited a-MoS ${ }_{\mathrm{x}}$ and b) exfoliated 1T-MoS 2 electrodes and corresponding Tafel slopes c) and d). Error bars were obtained by taking the deviation from the average value on three different electrodes for each pH.Different electrolytes were obtained as described in the methods part.

When increasing the $\mathrm{pH}$ above 1 , an increase in both the overpotentials and the Tafel slopes was observed for a-MoS $x$ and $1 \mathrm{~T}-\mathrm{MoS}_{2}$. As the proton concentration is decreasing,the proton adsorption step (Volmer step) could be expected to become rate limiting. This assumption is supported by the increase ofTafel slopes at higher $\mathrm{pH}$ to a value close to $120 \mathrm{mV}$ per decade found in the low overpotential region at $\mathrm{pH}=3$, value whichwould indicate the Volmerstep as rate determing step. Furthermore, RDE measurements recorded at $\mathrm{pH}=3$ demonstrate for both a-MoS and $1 \mathrm{~T}-\mathrm{MoS}_{2} \mathrm{a}$ behavior very similar to the one observed on precious metal ( $\mathrm{Pt}$, Ir and $\mathrm{Au}$ ) by Strmcniket $\mathrm{al}^{7}$. The first reduction wave at low overpotentialshows the typical exponentialbehavior corresponding to a 
kinetically limited region and the proton reduction mechanism. A plateau can then be seen at higher overpotential and can be attributed to the proton reduction reaction being limited by the proton diffusion. Finally, when the overpotentialis high enough, the water reduction reaction takes place and a typical exponential shape is once again observed. One can further notice that no diffusion limited region can be achieved for this mechanism, owing obviously from the large concentration of water.When further increasing the $\mathrm{pH}$ to 4 , the proton reduction wave becomesalmost undiscernible, and the water reduction is the main mechanism. Similar experiments were carried out

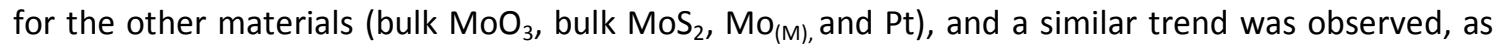
shown in Fig S4. This study further confirms that these two different HER mechanismsare universal and don't depend on the catalyst. This observation eventually setsa practical limitation for HER catalysts that cannot be used at low proton concentrations. Moreover, reasonable care must be exercise when tentatively comparing the water reduction mechanism for these compounds. Indeed, at similar current density, noise was found for the water splitting reaction at high $\mathrm{pH}$ while none was observed for the proton reduction reaction, which certainly indicates a modification of the electrode/electrolyte interfacial area.

Looking back at thedependenceof the Tafel slopeswith pH found for a-MoS $x$ and $1 \mathrm{~T}-\mathrm{MoS}_{2}$ (Fig. 3c and 3d) as well as for Pt (Fig. S5),the transition range was found independent on the materials and close to $\mathrm{pH} 2$ (slopes are found independent on the $\mathrm{pH}$ below this value while they increase with the $\mathrm{pH}$ above this value). Thisresult excludes the surface pKa as the sole origin for this shift and further reinforced the interpretation that two mechanisms are indeed at play.Similar observations were made by Haghighatet al.who proposed, based on calculations and electrochemical measurements, that both the reaction pathway and the mass-transfer limitation would drasticallyimpact the electron-transfer coefficient for the Volmer step ${ }^{27}$.

Nevertheless, under these conditions, the surface coverage of the catalysts might not be assumed independent of the overpotential, which could also lead to Tafel slopes of $120 \mathrm{mV}$ per decade even for the Tafel-Heyrovsky mechanism, as recently discussed by Shinagawaet $a{ }^{22}$. In order to better 
understand the influence of $\mathrm{pH}$ on the proton surface coverage and a possible shift in rate determining step, numerical calculations taking into account both the electron transfer (ButlerVolmer) and mass diffusion(Levich) were conducted.

For that, Butler-Volmer equation was used to describe the rate of electrochemical steps:

$$
k_{i}=k_{i}^{\circ} e^{-\left[\alpha_{i}\left(E-E_{i}^{\circ}\right)\right]}(1)
$$

with $\alpha_{i}$ being the transfer coefficient of the electrochemical step and $E_{i}^{\circ}$ the standard redox potential of the electrochemical couple considered. Mass transport was then assumed to follow the KouteckýLevich equation for RDE experiments:

$$
\begin{aligned}
& {[A]_{x=0}=[A]_{b u l k}+\frac{j}{2 F m_{A}}(2 . a)} \\
& m_{A}=0.620 \omega^{1 / 2} v^{-1 / 6} D_{A}^{2 / 3}(2 . b)
\end{aligned}
$$

$\omega$ being the rotation speed of the electrode, $v$ the solvent kinematic viscosity and $D_{A}$ the diffusion coefficient for the species $\mathrm{A}$ in the solution. Considering that the current density $j$ can be derived from the kinetics of the rate determining step,for instance a simple electrochemical step $A+e^{-} \rightarrow A^{-}$, numerical expression forjis then obtained by solving equation (3) for different values of $E$ and the three different rate determining steps considered in this work:

$$
j=\left[[A]_{\text {bulk }}+\frac{j}{2 F m_{A}}\right] k_{A / A^{-}}^{\circ} e^{-\left[\alpha_{i}\left(E-E_{A / A^{-}}^{\circ}\right)\right]}(3)
$$

All the equations relating to the different scenarios are given in the supplementary part.

First, the surface coverage was evaluated at $\mathrm{pH} 0$ for the three different scenarios: Tafel, Heyrosky and Volmer as rate determining steps (Fig. 4a). At low current density, the surface coverage was found to be almost null for every scenario, while at greater current density it is foundto be independent on the potential when the Tafel step is the rate determining one. Nevertheless, under our experimental conditions (current density $\leq 20 \mathrm{~mA} / \mathrm{cm}^{2}$ ), the surface coverage can be estimatedas 
very low and potential independent. As expected, a Tafel slope of about $40 \mathrm{mV}$ per decade as we experimentally observed in Fig.1for both $1 \mathrm{~T}-\mathrm{MoS}_{2}$ and a-MoS ${ }_{x}$ would indicate aVolmer-Heyrovsky mechanism, with the Heyrovsky step being the rate determining one (Fig. 4b).

Hence, to understand the increase of Tafel slope with pH previously observed, we then extended our analysis of the Heyrovsky scenario to the $0 \leq \mathrm{pH} \leq 4$ range. When increasing the $\mathrm{pH}$, a diffusion plateau for the proton reduction can be found above $\mathrm{pH} 2$ (Fig. 4c). Note that the calculated current densitiesare lower than the experimental ones owing from a poor determination of the real active surface area, as we previously discussed. Interestingly, the calculated Tafel slopes were found independent on the $\mathrm{pH}$ for this mechanism (Fig. 4 d), unlike what was experimentally measured (Fig. 3). Thus, the large increase of the Tafel slope with the $\mathrm{pH}$ previously measured for all the Mo-based catalysts must originate from a change in the rate determining step, with the proton adsorption Volmer step probably being limiting above $\mathrm{pH}=2$. 
a)

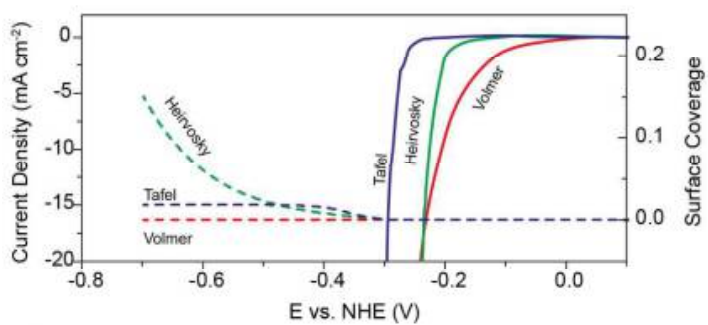

c)

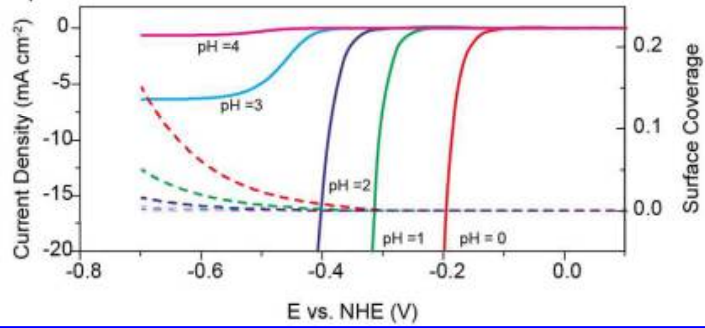

b)

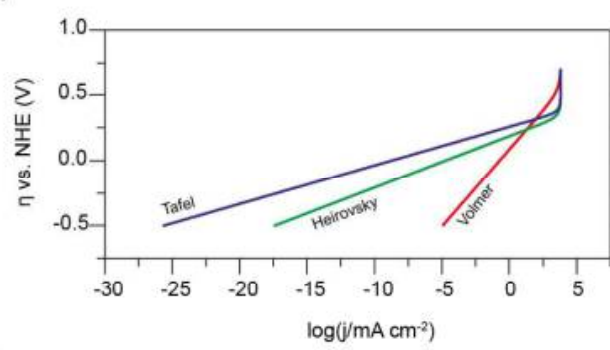

d)

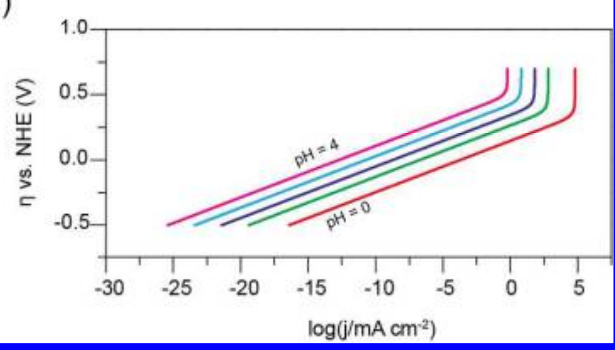

Figure 4.a) Polarization curves (solid lines) and potential dependent surface coverage (dashed lines) for different mechanism calculated using Butler-Volmer and Levich equations according to the rate determining step : Volmer (red), Heyrovsky (green) or Tafel (blue), b) corresponding Tafel plot, c) polarization curves (solid lines) and potential dependent surface coverage (dashed lines) considering the Heyrovsky step as rate determining for several $\mathrm{pH}$ values from 0 to 4 and d) corresponding Tafel plots. Those calculated curveswere obtained considering same conditions as in the experimental part (rotation $1,600 \mathrm{rpm}$ ).

\section{Electrochemical differentiation of active sites}

At that stage of the study, differences that might exist between exfoliated $1 \mathrm{~T}-\mathrm{MoS}_{2}$ nanosheets and amorphous $\mathrm{MoS}_{x}$ remain elusive. In order to get deeper insights into these inherent differences, we took advantage of the proton diffusion region observed at $\mathrm{pH} 3$ which can be very sensitive to the nature of interfacial water and therefore to the electrolyte composition.Indeed,at this $\mathrm{pH}$ value,cations from the supporting electrolyte are in large excess (200 $\mathrm{mM}$ ) compared to hydronium ions $(1.0 \mathrm{mM})$. An effect of the supporting electrolyte can then be expected, as it has already been discussed by several groups for $\mathrm{Pt}^{6,7,22}$, and reveal useful information about the catalysts. RDE experiments were performed using $\mathrm{Li}_{2} \mathrm{SO}_{4}, \mathrm{Na}_{2} \mathrm{SO}_{4}$ and $\mathrm{K}_{2} \mathrm{SO}_{4}$ as supporting electrolytes at pH 3 on a- 
$\mathrm{MoS}_{\mathrm{x}}, 1 \mathrm{~T}-\mathrm{MoS}_{2}$ and platinum electrodes. As shown in Fig. S6 and Fig.S7, no significant differences can be noticed for the proton reductionreaction or for the water reduction reaction for the three different materials as a function of the supporting electrolyte under rotation. This would indicate that mass diffusion from the bulk of the electrolyteto the surface of the electrode is either not drastically modified by the cations or not controlling the reactions.

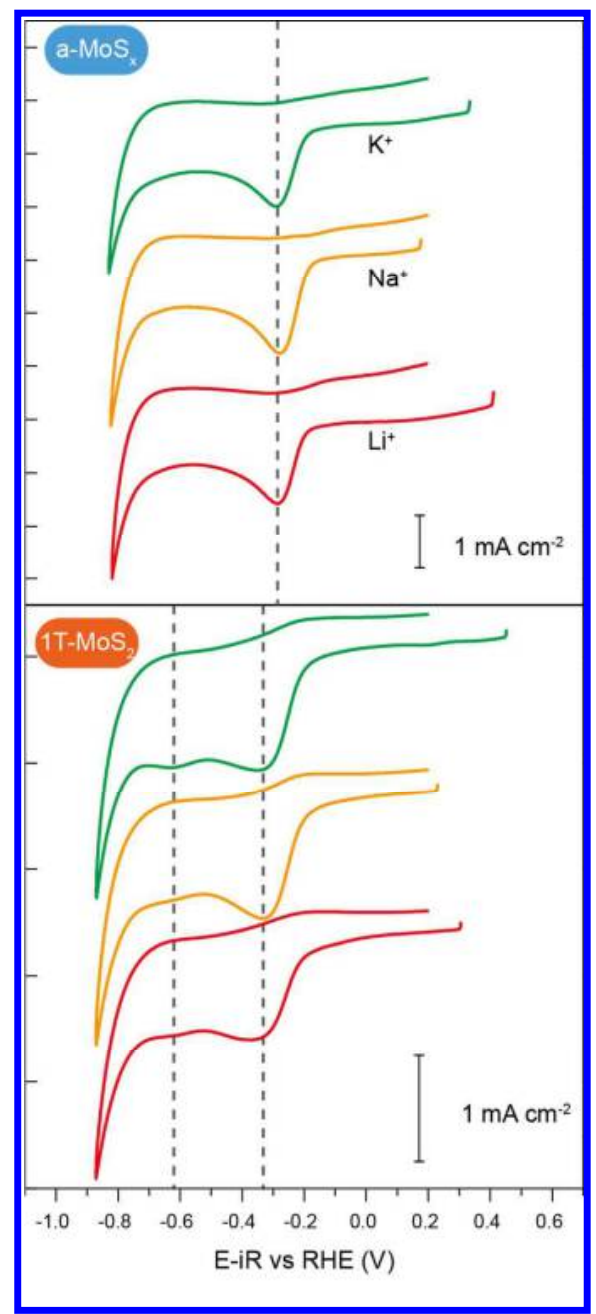

Figure 5. Static cyclovoltamograms obtained over electrodeposited a-MoS (top) and exfoliated 1T$\mathrm{MoS}_{2}$ (bottom) in several close to $\mathrm{pH} 3$ electrolytes obtained by mixing $1.8 \mathrm{mM} \mathrm{H}_{2} \mathrm{SO}_{4}$ and $98.2 \mathrm{mM}$ $\mathrm{A}_{2} \mathrm{SO}_{4}, \mathrm{~A}$ being respectively $\mathrm{Li}^{+}$(red), $\mathrm{Na}^{+}$(yellow) and $\mathrm{K}^{+}$(green). A $100 \mathrm{mV} \mathrm{s}^{-1}$ sweeping rate was used For a better readability two different $\mathrm{y}$-axis scales are used, each tick corresponding to $1 \mathrm{~mA}$ $\mathrm{cm}^{-2}$.

However,under steady conditions, i.e. with no rotation, CV measurements reveal significant 
differences between a-MoS and 1T-MoS . As shown in Figure5, the nature of the supporting electrolyte does not modify the electrochemical behavior for a-MoS ${ }_{x}$ which exhibits only one reduction peak at around $-0.3 \mathrm{~V}$ vs. RHE that can reasonably be attributed to the proton reduction. This result suggests that the Gibbs free energy of formation $\left(\Delta G{ }^{*}{ }_{H}\right)$ of the reaction intermediate *His not modified for the different cations. Unlike a-MoS ${ }_{x}$, the electrochemical behavior for 1T-MoS 2 was found dependent on the cation. Hence, two reduction peaks before the water splittingregion below $0.8 \mathrm{~V}$ can be found for $\mathrm{K}^{+}$, while the second peak at higher overpotential (-0.6 V vs. RHE) almost vanished for $\mathrm{Li}^{+}$and $\mathrm{Na}^{+}$. Those two peaks arelikely related to two different proton reduction reaction pathways, corresponding to the presence of two different reaction intermediates for the HER. Hence,two different types of active sitesor two different mechanisms for the same active sites must co-existfor1T-MoS , unlike a-MoS for which all active sites presumably undergo the same reaction pathway. We could be tempted to attribute the first reduction peak to the proton reduction by the most active sites located on the edges of $1 \mathrm{~T}-\mathrm{MoS}_{2}$, while the second one could be related to less active sites located in the basal planes as suggested by recent reports ${ }^{28}$.Several relevant parameters are usually discussed for the influence of cations on electrocatalysts properties such as the solvation strength or the modification of the hydrogen bonds network ${ }^{6}$. In light of previousX-ray diffraction (XRD) and solid-state nuclear magnetic resonance (ssNMR) reports for which thewater environment in intercalated restacked $1 T-\mathrm{MoS}_{2}$ nanosheets was studied ${ }^{29,30}$, one can tentatively explain our observations. Hence, these studies reveal that water molecules are differently coordinated around the different cations: in presence of $\mathrm{Li}^{+}$or $\mathrm{Na}^{+}, 6$ water molecules are solvating the cation while only two are solvating $\mathrm{K}^{+}$. We could therefore explain our results by the very high sensitivity of the less active site for $1 \mathrm{~T}-\mathrm{MoS}_{2}$ on the structure of the interfacial water.We then performed the same experiments on platinum electrodes for whichonly one reduction peak independent on the nature of the supporting electrolyte can be seen (Fig. S9). This result therefore corroborates the existence of a single type of active site for a-MoS . Finally, the shift of about $50 \mathrm{mV}$ in the reduction peak observed between a-MoS $\left(-0.28 \mathrm{~V}\right.$ vs. RHE) and $1 \mathrm{~T}-\mathrm{MoS}_{2}(-0.32 /-0.34 \mathrm{~V}$ vs. RHE depending on the cation) 


\section{1}

2

3

4

5

6

7

8

indicates different energy for the ${ }^{*} \mathrm{H}$ intermediate of the proton reduction reaction for these two catalysts, which suggests differences between the active sites.

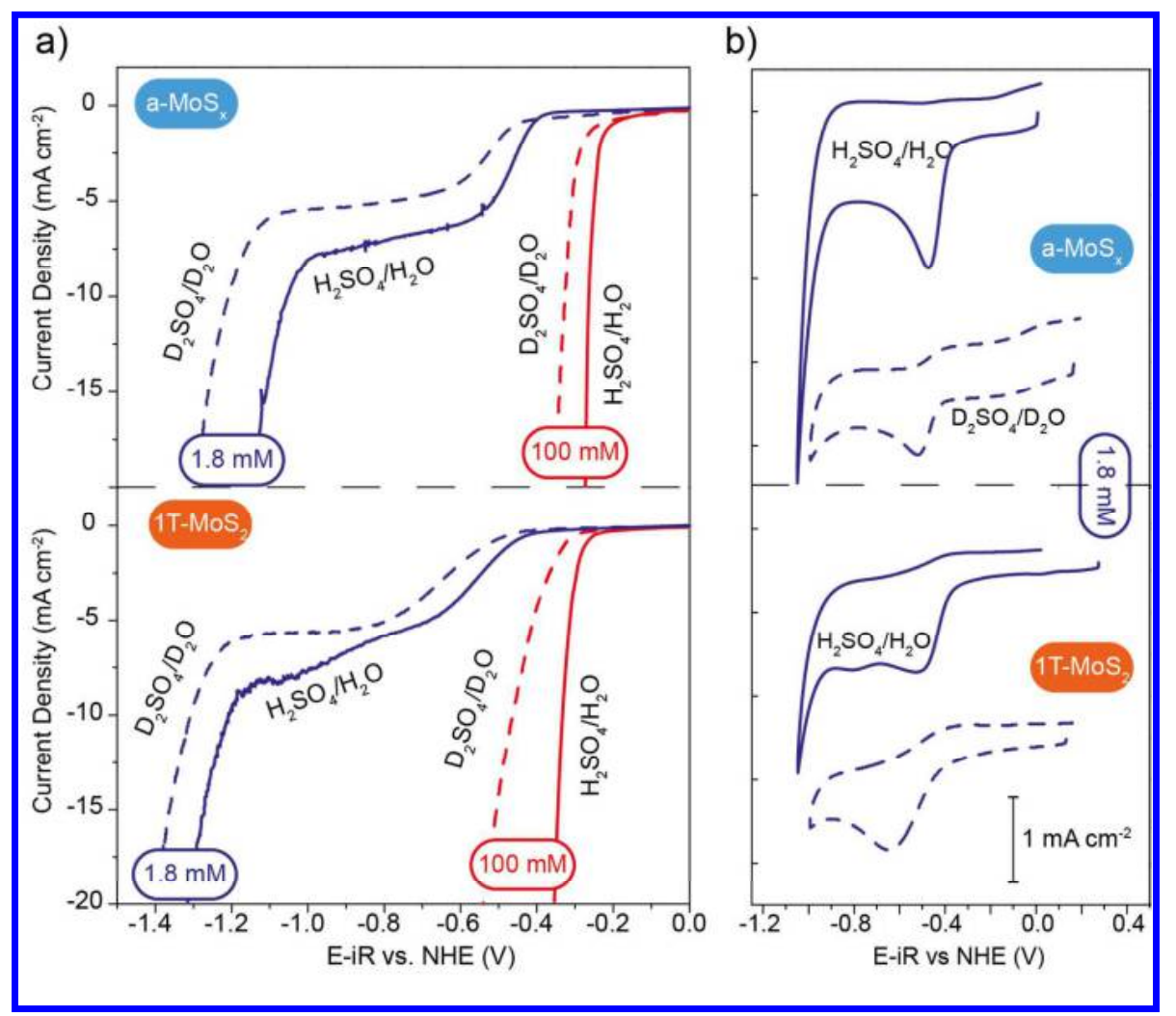

Figure6. a) Polarization curves recorded in normal (solid lines) or deuterated electrolytes (dashed lines) $100 \mathrm{mM}$ acid (red) and $1.8 \mathrm{mM}$ (blue) at $20 \mathrm{mV} \mathrm{s}^{-1}$ using a RDE at 1,600 rpm and b) corresponding static CVs recorded in the $1.8 \mathrm{mM}$ acid electrolytes at $100 \mathrm{mV} \mathrm{s} \mathrm{s}^{-1}$ over amorphous $\mathrm{MoS}_{2}$ (top) and exfoliated 1T-MoS (bottom) electrodes. In b), each tick on the left axis corresponds to $1 \mathrm{~mA} \mathrm{~cm}^{-2}$.

To clarify our observations and further understand the complexity of the interactions catalyst/interfacial water,isotopic effects were studied. For that, several $\mathrm{D}_{2} \mathrm{SO}_{4}$ in $\mathrm{D}_{2} \mathrm{O}$ electrolytes were employed and electrochemical behaviors compared with those previously measured using $\mathrm{H}_{2} \mathrm{SO}_{4}$ in $\mathrm{H}_{2} \mathrm{O}$ electrolytes. Unlike previous experiments, results are reported in Fig. 6vs. the normal hydrogen electrode ( $\mathrm{NHE})$ as $\mathrm{pH}$ and $\mathrm{pD}$ cannot be simply compared.Before any interpretations, it should be reminded that using deuterium strongly modifies the electrolyte properties, especially by decreasing the diffusion coefficient of the reactant $\left(4.10^{-5} \mathrm{~cm}^{-2} \mathrm{~s}^{-1}\right.$ for $\mathrm{D}_{3} \mathrm{O}^{+}$in $\mathrm{D}_{2} \mathrm{O}$ compared to $7.10^{-}$ 
${ }^{5} \mathrm{~cm}^{-2} \mathrm{~s}^{-1}$ for $\mathrm{H}_{3} \mathrm{O}^{+}$in $\mathrm{H}_{2} \mathrm{O}^{31}$ ) as well as shifting the standard potential for the reaction $\left(\mathrm{E}^{\circ}\left(\mathrm{D}^{+} / \mathrm{D}_{2}\right) \approx-6\right.$ mVvsRHE ${ }^{32,33}$ ). While no drastic modifications were found for $\mathrm{Pt}$ when comparing $\mathrm{D}_{2} \mathrm{O}$ and $\mathrm{H}_{2} \mathrm{O}$ measurements (as shown in Fig. S8), a large shift to greater overpotential is observed for a-MoS $x$ and $1 \mathrm{~T}-\mathrm{MoS}_{2}$ when using $\mathrm{D}_{2} \mathrm{O}$ solutions. Regarding a-MoS , limitations related to proton diffusion within the porosity of the film could explain this shift.Nevertheless, since 1T-MoS 2 catalyst is dense, the shift must originate from other limitations. Tafel slopes were then calculated for both compounds in the $100 \mathrm{mMH}_{2} \mathrm{SO}_{4} / \mathrm{D}_{2} \mathrm{SO}_{4}$ electrolytes. Hence the slope measured for a-MoS in the deuterated electrolyte (46 $\pm 5 \mathrm{mV} /$ decade) is similar to the slope obtainedin $\mathrm{H}_{2} \mathrm{O}$ electrolyte $(50 \pm 7 \mathrm{mV} /$ decade), which advocates for limitations related to diffusion within the film. However, for $1 \mathrm{~T}-\mathrm{MoS}_{2}$ the Tafel slope significantly increaseswhen using deuterated electrolyte $\left(50 \pm 2 \mathrm{mV} /\right.$ decade in $\mathrm{H}_{2} \mathrm{O}$ and $66 \pm 8$ $\mathrm{mV} /$ decade in $\mathrm{D}_{2} \mathrm{O}$ ). We could be tempted to explain this observation by stronger $\mathrm{D}$ - $\mathrm{D}$ bond when compared to $\mathrm{H}-\mathrm{H}$ bond (respectively 443 and $436 \mathrm{~kJ} \mathrm{~mol}^{-1}$ ) which would slower the rate limiting step. Nevertheless, similar behavior should then be expected for a-MoS. Hence, the change in Tafel slopes suggests than the free enthalpy of formation of the HER intermediate for $1 \mathrm{~T}-\mathrm{MoS}_{2}$ is modifiedwhen using deuterium,or that the surface coverage of ${ }^{*} D$ decreases, hence slowing down the rate for the $D_{2}$ evolution step.

When decreasing the concentration of sulfuric acid to $1.8 \mathrm{mM}$ (deuterated or not)similar observations can be made. More specifically, CVs recorded without rotation highlight the fundamental differences existing between a-MoS and $1 \mathrm{~T}-\mathrm{MoS}_{2}$ (Fig. 6b). For a-MoS , a slight shift corresponding to the proton adsorption and reduction peak is observed in deuterated solvent, associated with a weaker intensity as expected from the limitations related to diffusion within the film. For $1 \mathrm{~T}-\mathrm{MoS}_{2}$, not only a shift greater than $100 \mathrm{mV}$ is measured for the proton reduction peak, but the second peak previously observed in Fig. 5 disappeared. Hence, from our combined isotopic and cation studies, one can conclude that the active sites are different for a-MoS ${ }_{x}$ and $1 \mathrm{~T}-\mathrm{MoS}_{2}$, with the active sites being very dependent on the nature of the interfacial water for $1 \mathrm{~T}-\mathrm{MoS}_{2}$. 


\section{Discussion}

The results presented above reveal how interfacial interactions involved in the proton reduction reaction, and more generally in electrochemical processes, govern the kinetics of these processes. As mentioned earlier in this work, the study of the HER is challenging because of its fast kinetics, especially in low pH conditions. Fortunately, as shown in Figure 7, it is possible to gain deeper insights into the catalysts operation by triggering specific interactions. In low pH conditions, as no supporting salt is added, the only interactions at play are the ones between the catalyst and the hydronium ion, partially solvated by water molecules. To reveal these interactions, deuterated electrolytes have been used. Hence, the kinetics of the HER was shown to be altered by the $\mathrm{D}^{+} / \mathrm{H}^{+}$ isotopic effect for $1 \mathrm{~T}-\mathrm{MoS}_{2}$, while its remains independent on this effect for other catalysts such as a$\mathrm{MoS}_{\mathrm{x}}$ and Pt. This strategy has the advantage to be direct and to give information about the specific interactions governing the HER on the surface of catalysts without further modifying the proton (or deuterium) concentration. Furthermore, by increasing the $\mathrm{pH}$ to 3 and employing different conductive salts, we could slower the HER kinetics and demonstrate the complexity of this reaction on the surface of Mo-based catalysts. It could be tempting to uniquely attribute the effects observed on $1 \mathrm{~T}-\mathrm{MoS}_{2}$ and the absence of effect for a-MoS to a specific interaction between the cation and the active site for $1 \mathrm{~T}-\mathrm{MoS}_{2}$, which differs from a-MoS $\mathrm{x}$ as no cationic effect would be expected if the cation is not electroactive (which would result from no specific interaction between the cation and the catalyst) ${ }^{34}$. However, coupling this study with results obtained in deuterated electrolytes at the same $\mathrm{D}^{+} / \mathrm{H}^{+}$concentration (i.e. $\mathrm{pH}$ or $\mathrm{pD}=3$ ), we could undoubtedly show that the complex interactions between the catalyst surface, hydronium ions and cations from the supporting electrolyte govern the HER kinetics under these conditions. Furthermore, this unique approach could also alleviate the difficulties related to the study of HER catalysts by highlighting the differences existing between the electrochemically active sites for $1 \mathrm{~T}-\mathrm{MoS}_{2}$ and a-MoS . Finally, the interactions cations-catalyst-water appear not to be critical for the water reduction reaction at $\mathrm{pH}=4$ (Figure 6 , 
right). Indeed, the energy required for breaking $\mathrm{O}-\mathrm{H}$ bond in water $\left(\approx 500 \mathrm{~kJ} \mathrm{~mol}^{-1}\right)$ is greater than the one involved for weaker interactions such as hydrogen bonding.

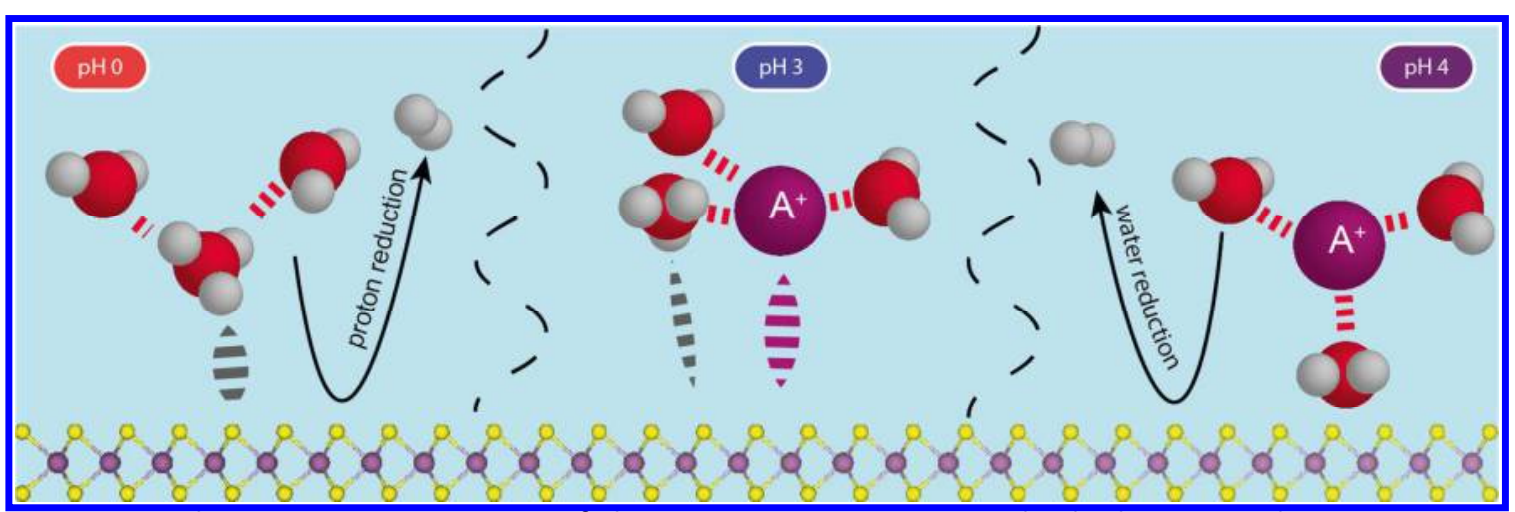

Figure 7. Schematic representation of the interactions governing the hydrogen evolution reaction kinetics on molybdenum sulfides catalysts. At $\mathrm{pH}=0$ (left), the proton reduction takes place where only hydronium interaction with the surface of the catalysts play a role. At pH $=4$ (right), the water reduction reaction takes place for which interaction with cations from the supporting electrolyte does not play a critical role on the HER kinetics.Finally, at $\mathrm{pH}=3$ for which both proton reduction and water reduction reactions are in competition (center), interactions between the catalyst, water and cations from the supportingelectrolyteare essential for the HER kinetics.

\section{Conclusion}

We have demonstrated in this work the ubiquity of the two HER mechanisms on the surface of Mobased HER catalysts: the proton reduction reaction at low $\mathrm{pH}$ (high proton concentration) and the water reduction reaction at high $\mathrm{pH}$ (low proton concentration). We could further reveal that while the proton reduction reaction is catalyzed by Mo-based catalysts, i.e. the proton adsorption energy controls the rate of the reaction, the kinetics for the water reduction reaction was found almost independent on the catalysts. This further supports previous assumptions that the kinetics for this reaction is largely dominated by the energy required to break the $\mathrm{O}-\mathrm{H}$ bond in water. From this observation, we then proposed a methodology to recognize the differences existing between the active sites for amorphous $\operatorname{MoS}_{x}$ films and crystalline exfoliated $1 \mathrm{~T}-\mathrm{MoS}_{2}$. By varying the supporting 
1

2

3

4

5

6

7

8

electrolyte, we found that a-MoS shows only one active site which is largely independent on the nature of the supporting electrolyte. In contrary, two actives sites were found for $1 \mathrm{~T}-\mathrm{MoS}_{2}$, with both of them being highly dependent on the nature of the interfacial water that can be modified by changing the cations in solution or replacing protons by deuterium. This work highlights the opportunity given by specific interactions to study and better understand active sites for HER catalysts, which we hope will lead to the development of better cost-effective catalysts.

\section{Materials \& methods}

\section{Materials}

All chemicals (except $\mathrm{MoS}_{2}$ nanosheets suspension) were purchased from commercial suppliers, and used without further purification. Ultrapure Mili-Q water $(18.2 \mathrm{M} \Omega \cdot \mathrm{cm})$ was used in all experiments. Glasswares used were rinsed 3 times with ultrapure water prior to be used.

\section{Electrodes preparation}

Prior to any deposition of active material, mirror polished GC electrodes (Pine research) were polished using an ultrafine alumina slurry $(0.05 \mu \mathrm{m}$, Pine research) on a microcloth polishing disk (Pine research). As polished electrodes were sonicated in a 50:50 ethanol/water solution, two times for 15 minutes to remove Alumina particles.Same procedure was applied for the Pt disk electrode (Pine research).

a-MoS electrodes were electrodeposited on GC electrodes by 50 consecutives CVsperformed in approximatively $5 \mathrm{~mL}$ of a $1 \mathrm{mM} \mathrm{MoS}_{4}\left(\mathrm{NH}_{4}\right)_{2}$ (99.97\%, Sigma-Aldrich, stored in a Ar filled glovebox) solution with a $0.1 \mathrm{M} \mathrm{KCl}$ (>99\%, Alfa-Aesar) used as supporting electrolyte between $-0.948 \mathrm{~V}$ and0.252 V vs. $\mathrm{AgCl} / \mathrm{Ag}(3 \mathrm{M} \mathrm{KCl})$ reference electrode. A Pt wire was used as counter electrode. CorrespondingCVs are shown in Fig. S9. The influence of the Pt counter electrode either on the deposition of a-MoS or on the HER activity was dismissed by depositing and testing a-MoS electrodes at $\mathrm{pH} 0$ and $\mathrm{pH} 3$ using a graphite rod as the counter electrode. Electrodes deposited using a Pt wire as the counter electrode did not exhibit greater performances than those deposited using a Pt wire. Also, electrodes tested using a graphite rod behaved similarly than when tested with a graphite rod (Fig S13). 
$1 \mathrm{~T}-\mathrm{MoS}_{2}$ nanosheets were prepared as described elsewhere ${ }^{16}$.Details and characterizations (Raman spectroscopy Fig.S10 and X-Ray Photoelectron Spectroscopy Fig. S11) are given in the supplementary methods.

Molybdenum metal(3-7 $\mu \mathrm{m}$ particles, 99.95\%, Alfa Aesar), $\mathrm{MoO}_{3}$ (99.5\%, Sigma-Aldrich), bulk $\mathrm{MoS}_{2}$ (99\%, Alfa Aesar) electrodes were prepared by drop-casting $10 \mu \mathrm{L}$ of an ink on GC electrodes. The ink was prepared by mixing $20 \mathrm{mg}$ of active compound, with $5 \mathrm{mg}$ of active carbon in $5 \mathrm{~mL}$ of THF. The as prepared ink was sonicated for $30 \mathrm{~min}$ and then $130 \mu \mathrm{L}$ of Nafion $(5 \%$ weight in $1 / 1$ water/1propanol, Alfa Aesar) was added as a binder after what the ink was sonicated for 30 min.

\section{Electrochemical measurements}

Test at $\mathrm{pH} 0$ and $\mathrm{pH}$ dependence study were conducted in $\mathrm{H}_{2} \mathrm{SO}_{4}$ electrolytes prepared from $96 \%$ sulfuric acid (Sigma-Aldrich, Sial). For electrolytes containing less than $100 \mathrm{mM}$ of $\mathrm{H}_{2} \mathrm{SO}_{4}$, a supporting electrolyte was used to limit the ohmic drop. These electrolytes were prepared by mixing a $100 \mathrm{mM}$ $\mathrm{H}_{2} \mathrm{SO}_{4}$ solution with a $100 \mathrm{mM}$ supporting electrolyte. For instance, to obtain the $\mathrm{pH} 2$ electrolyte, 18 $\mathrm{mL}$ of $100 \mathrm{mM} \mathrm{H}_{2} \mathrm{SO}_{4}$ was mixed with $100 \mathrm{mM} \mathrm{K}_{2} \mathrm{SO}_{4}$ electrolyte to get a final volume of $100 \mathrm{~mL}$.pH 3 and $\mathrm{pH} 4$ electrolytes were obtained using respectively $1.8 \mathrm{mM}$ and $0.18 \mathrm{mM} \mathrm{H}_{2} \mathrm{SO}_{4}$ concentrations. $\mathrm{K}_{2} \mathrm{SO}_{4}(>99 \%$, Alfa-Aesar) was used for all the tests, unless for cation dependence study for which $\mathrm{Li}_{2} \mathrm{SO}_{4}\left(99 \%\right.$, monohydrate, Alfa-Aesar), $\mathrm{Na}_{2} \mathrm{SO}_{4}(>99 \%$, anhydrous, Alfa-Aesar) were used. Deuterated electrolytes were prepared the same way except that water was replaced by $D_{2} \mathrm{O}$ (Sigma-Aldrich, 99\% D) and sulfuric acid by $\mathrm{D}_{2} \mathrm{SO}_{4}$ (Sigma Aldrich, 99.5\% D).

Electrolytes were degassed in order to eliminate $\mathrm{CO}_{2}$ and $\mathrm{O}_{2}$ by bubbling $\mathrm{Ar}$ (Linde, purity 5.0) for at least $30 \mathrm{~min}$ before first experiment and for a smaller time between different experiments. $\mathrm{pH}$ values of electrolytes were measured and checked by measuring the voltage $E$ between the RHE electrode and a calomel saturated reference electrode, for which the potential was considered to be $240 \mathrm{mV}$, $\mathrm{pH}$ is then given by the following equation $p H=(E-0.240) / 0.059$ derived from Nernst equation.

All the electrodes were "activated" by being cycled at least 1 cycle until the current density reaches $20 \mathrm{~mA} / \mathrm{cm}^{2}$. Polarization curves were recorded on fresh electrodes to probe each time a clean surface(typically second cycle for a-MoS and $1 \mathrm{~T}-\mathrm{MoS}_{2}$, first for Pt andMoS $\mathrm{Mulk}_{2} \mathrm{MoO}_{3}$ and $\mathrm{Mo}_{(\mathrm{M})}$, except when stability test where performed). As described in the literature, the as deposited a-MoS undergoes a reduction which is assumed to be $\mathrm{MoS}_{2+\mathrm{x}}->\mathrm{MoS}_{2}$ in the first cycle ${ }^{21}$, as shown in Fig. S12. 
Data were acquired using a Biologic VSP potentiostat. Ohmic drop compensation was measured using impedance spectroscopy after electrochemical measurements, and corrected during the data treatment. Typical values ranged from around 3-5 Ohms in $\mathrm{pH}=0$ electrolytes to about 35 Ohms in $\mathrm{pH} 4$ electrolytes.

\section{Supporting Information.}

Details about the numerical model, supplementary electrochemical measurements and characterization for the $1 \mathrm{~T}-\mathrm{MoS}_{2}$ material.

\section{Acknowledgement.}

N.D. would like to acknowledge ENS for financial support.

\section{References}

(1) Bruce, P. G.; Freunberger, S. A.; Hardwick, L. J.; Tarascon, J.-M. Nat. Mater.2012, 11, 19-29.

(2) Licht, S.; Cui, B.; Stuart, J.; Wang, B.; Lau, J. Enerav Environ. Sci.2013, 6 , 3646-3657.

(3) Midilli, A.; Ay, M.; Dincer, I.; Rosen, M. A. Renew. Sustain. Enerav Rev.2005, 9 , 255-271.

(4) Dau, H.; Limberg, C.; Reier, T.; Risch, M.; Roggan, S.; Strasser, P. ChemCatChem2010, 2, 724761.

(5) Hong, W. T.; Risch, M.; Stoerzinger, K. A.; Grimaud, A.; Suntivich, J.; Shao-Horn, Y. Energy Environ. Sci.2015, 8, 1404-1427.

(6) Subbaraman, R.; Tripkovic, D.; Strmcnik, D.; Chang, K.-C.; Uchimura, M.; Paulikas, A. P.; Stamenkovic, V.; Markovic, N. M. Science2011, 334, 1256-1260.

(7) Strmcnik, D.; Uchimura, M.; Wang, C.; Subbaraman, R.; Danilovic, N.; van der Vliet, D.; Paulikas, A. P.; Stamenkovic, V. R.; Markovic, N. M. Nat. Chem.2013, 5, 300-306.

(8) Stamenkovic, V. R.; Strmcnik, D.; Lopes, P. P.; Markovic, N. M. Nat. Mater.2016, 16, 57-69.

(9) Durst, J.; Siebel, A.; Simon, C.; Hasché, F.; Herranz, J.; Gasteiger, H. A. Energy Environ. Sci.2014, 7, 2255. 
(10) Ledezma-Yanez, I.; Wallace, W. D. Z.; Sebastián-Pascual, P.; Climent, V.; Feliu, J. M.; Koper, M. T. M. Nat. Enerav2017, 2, 17031.

(11) Costentin, C.; Giovanni, C. D.; Giraud, M.; Savéant, J.-M.; Tard, C. Nat. Mater.2017, 16, 1016.

(12) Nørskov, J. K.; Bligaard, T.; Logadottir, A.; Kitchin, J. R.; Chen, J. G.; Pandelov, S.; Stimming, U. J. Electrochem. Soc.2005, 152, J23.

(13) Morales-Guio, C. G.; Stern, L.-A.; Hu, X. Chem. Soc. Rev. 2014, 43, 6555-6569.

(14) Hinnemann, B.; Moses, P. G.; Bonde, J.; Jørgensen, K. P.; Nielsen, J. H.; Horch, S.; Chorkendorff, I.; Nørskov, J. K. J. Am. Chem. Soc.2005, 127, 5308-5309.

(15) Jaramillo, T. F.; Jørgensen, K. P.; Bonde, J.; Nielsen, J. H.; Horch, S.; Chorkendorff, I. Science2007, 317, 100-102.

(16) Benck, J. D.; Hellstern, T. R.; Kibsgaard, J.; Chakthranont, P.; Jaramillo, T. F. ACS Catal.2014, 4, $3957-3971$.

(17) Voiry, D.; Salehi, M.; Silva, R.; Fujita, T.; Chen, M.; Asefa, T.; Shenoy, V. B.; Eda, G.; Chhowalla, M. Nano Lett.2013, 13, 6222-6227.

(18) Voiry, D.; Fullon, R.; Yang, J.; de Carvalho Castro e Silva, C.; Kappera, R.; Bozkurt, I.; Kaplan, D.; Lagos, M. J.; Batson, P. E.; Gupta, G.; Mohite, A. D.; Dong, L.; Er, D.; Shenoy, V. B.; Asefa, T.; Chhowalla, M. Nat. Mater.2016, 15, 1003-1009.

(19) Lu, A.-Y.; Yang, X.; Tseng, C.-C.; Min, S.; Lin, S.-H.; Hsu, C.-L.; Li, H.; Idriss, H.; Kuo, J.-L.; Huang, K.-W.; Li, L.-J. Smal/2016, 12, 5530-5537.

(20) Merki, D.; Fierro, S.; Vrubel, H.; Hu, X. Chem. Sci.2011, 2, 1262-1267.

(21) Vrubel, H.; Hu, X. ACS Catal.2013, 3, 2002-2011.

(22) Shinagawa, T.; Garcia-Esparza, A. T.; Takanabe, K. Sci. Rep.2015, 5, 13801.

(23) Deng, Y.; Ting, L. R. L.; Neo, P. H. L.; Zhang, Y.-J.; Peterson, A. A.; Yeo, B. S. ACS Catal.2016, 6, 7790-7798.

(24) Tran, P. D.; Tran, T. V.; Orio, M.; Torelli, S.; Truong, Q. D.; Nayuki, K.; Sasaki, Y.; Chiam, S. Y.; Yi, R.; Honma, I.; Barber, J.; Artero, V. Nat. Mater.2016, 15, 640-646. 
1

2

3

4

5

6

7

8

9

10

(25) Grimaud, A.; Hong, W. T.; Shao-Horn, Y.; Tarascon, J.-M. Nat. Mater.2016, 15, 121-126.

(26) Liu, Y.; Wu, J.; Hackenberg, K. P.; Zhang, J.; Wang, Y. M.; Yang, Y.; Keyshar, K.; Gu, J.; Ogitsu, T.; Vajtai, R.; Lou, J.; Ajayan, P. M.; Wood, B. C.; Yakobson, B. I. Nat. Energy2017, 6, 2017127.

(27) Haghighat, S.; Dawlaty, J. M. J. Phys. Chem. C2016, 120, 28489-28496.

(28) Zhang, J.; Wu, J.; Guo, H.; Chen, W.; Yuan, J.; Martinez, U.; Gupta, G.; Mohite, A.; Ajayan, P. M.; Lou, J. Adv. Mater.2017, 29, 1701955.

(29) Alexiev, V.; Meyer zu Altenschildesche, H.; Prins, R.; Weber, T. Chem. Mater.1999, 11, 17421746.

(30) Acerce, M.; Voiry, D.; Chhowalla, M. Nat. Nanotechnol.2015, 10, 313-318.

(31) Benderskij, V.A., Krivenko, A.G., \& Rukin, A.N. Khimiya Vysok. Ehnergij1980, 14, 400-405.

(32) Mclntyre, J. D. E.; Peck, W. F. J. Electrochem. Soc.1970, 117, 747-751.

(33) Mclntyre, J. D. E.; Salomon, M. J. Phys. Chem.1968, 72, 2431-2434.

(34) Herranz, J.; Durst, J.; Fabbri, E.; Patru, A.; Cheng, X.; Permyakova, A. A.; Schmidt, T. J. Nano Energy2016, 29, 4-28. 


\section{FOR TABLE OF CONTENTS ONLY}

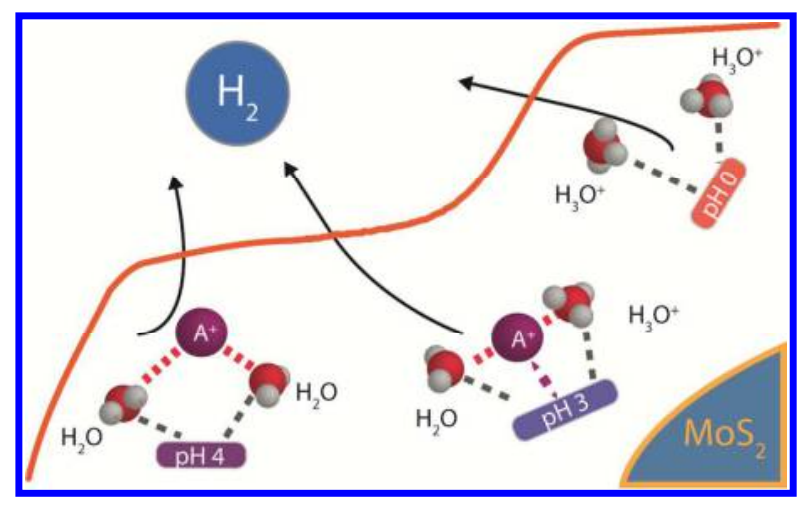

